Institute of $\mathbf{F}_{\text {ood and }} \mathbf{A}_{\text {gricultural }} \mathbf{S}_{\text {ciences }}$

\title{
Tomatoes and Other Seed-Bearing Vegetables: Safe Handling Practices for Consumers ${ }^{1}$
}

\section{Amy Simonne ${ }^{2}$}

A variety of fruits and vegetables should be part of one's healthy diet. Tomatoes and other seed-bearing vegetables provide nutrients important to our health. They can also cause foodborne illness if not handled properly. Here are steps you can take to reduce your risk of foodborne illness from tomatoes and other delicate seed bearing vegetables.

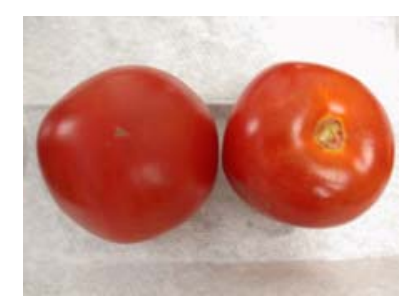

\section{Where You Shop:}

- Buy tomatoes and other seed-bearing vegetables, such as peppers, that are not bruised or damaged.

- Keep fresh tomato and other seed-bearing vegetables separate from raw meat, poultry and fish.

- Fresh-cut tomatoes and other vegetables should be kept refrigerated.

\section{At Home:}

- Whole tomatoes and ripe peppers do not need refrigeration. They actually develop less flavor if they are stored cold. Other seedbearing vegetables, such as green peppers and cucumbers must be kept refrigerated.
- All fresh produce should be refrigerated within two hours of peeling or cutting.

- Leftover cut tomato should be discarded after two hours at room temperature.

\section{During Preparation}

- Wash hands with hot, soapy water before and after:

- handling fresh produce

- handling raw meat, poultry, or seafood

- using the bathroom

- changing diapers

- handling pets

- Wash tomatoes and other seed-bearing vegetables with cool tap water just before preparing or eating. Don't use soap or detergents.

1. This publication is FCS8738, one of a series of the Department of Family, Youth and Community Sciences, Cooperative Extension Service, IFAS, University of Florida. Publication: November 2002. Please visit the EDIS Web site at http://edis.ifas.ufl.edu

2. Amy Simonne, Ph.D., assistant professor, Department of Family, Youth and Community Sciences, Cooperative Extension Service, IFAS, University of Florida, Gainesville, 32611. Reviewed by Linda B. Bobroff, Ph.D., RD, LD/N, associate professor, Department of Family, Youth and Community Sciences, Jeffrey K. Brecht, Ph.D. professor, Department of Horticultural Science, Cooperative Extension Service, IFAS, University of Florida, Gainesville, 32611. 


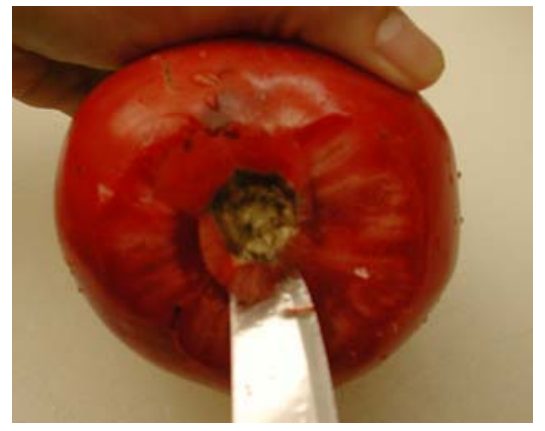

- Certain types of tomatoes are placed in a dump tank containing a sanitizer after they are harvested. Bacteria that survive this treatment are usually around the stem end. Always cut away the stem end of the tomato with a clean knife before slicing or chopping for eating raw.

- Do not consume seed-bearing vegetables such as peppers that have holes. They could be contaminated.

- Discard vegetables that have holes or that are bruised or damaged. Microbes can hide or invade the rest of the fruit from the damaged areas.

- Wash cutting boards, dishes, utensils, and counter tops often. Use hot, soapy water and rinse well. Sanitize them after contact with fresh produce, or raw meat, poultry, or seafood (see box).

- Sanitize kitchen sink frequently to prevent a build up of microbes.

- Do not cross contaminate! Use clean cutting boards and utensils for fresh produce.
- If you can, use separate cutting boards for raw meat, poultry, and seafood.

- Do not consume ice that has come in contact with fresh produce or other raw products.

- Use a cooler with ice or ice gel packs when you take perishable foods outdoors. This includes cut fresh fruits and vegetables.

\section{To sanitize cutting boards, dishes, utensils:}

- Mix one teaspoon chlorine bleach in one quart water

- Pour the mixture onto all surfaces or submerge the appropriate items in the solution above and let sit at least one minute

- Rinse surfaces well with hot running water

Counter tops can be sanitized by using the above solution mix, sanitizing sprays or wipes as an additional safety measure.

Following these steps will help reduce your risk of foodborne illness from fresh produce.

\section{For more information,} visit the Food and Drug Administration (FDA) website at: http://www.fda.gov or call FDA Consumer Inquiries at 1-888-SAFEFOOD (a toll-free number).

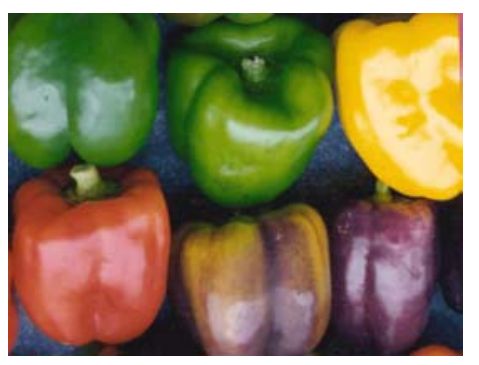

